CLINICAL LECTURES

ON

MENTAL AND CEREBRAL DISEASES.

BY J. CRICHTON BROWNE, M.D., F.R.S.E.,

Medical Director, West Riding Asylum; Lecturer on Mental Diseases to the Leeds School of Medicine; etc.

\section{I. - BRAIN-WASTING.}

Gentlemen, - You are aware that if mechanical pressure is applied to a motor nerve in such a manner that, beginning with the slightest contact, it is gradually and steadily increased, even until the nerve is destroyed at the point of application, no convulsions or spasms, but only deadness and abolition of function are produced; but that, on the other hand, if even a less degree of pressure is suddenly exerted, violent convulsions and agitations inevitably ensue. Now, what I desire to bring before you in the first place, to-day, is that moral or mental pressure on the brain has two distinct sets of consequences according to the mode of its application, corresponding with the two sets of consequences of mechanical pressure on a motor nerve, to which we have referred. Having long felt the importance of arriving at something more definite and satisfactory than the hazy generalisations now in vogue as to the effects of intense emotion or excessive intellectual strain in the production of mental derangements, I have paid some attention to the subject, and have convinced myself on this point; that a sudden emotion-a flash of joy or a pang of grief for which there had been no preparation, and a hastily imposed intellectual burden-an arduous task undertaken by an untrained mind, are most likely to produce mania or some acute form of mental disorder; and that a gradual emotion-pleasurable excitement "long drawn out," or a canker care quietly eating its way, and a slowly imposed intellectual burden-the cumulative weight of a course of study-are most likely to produce dementia or a progressive impairment of the faculties. I shall upon a future occasion describe to you several cases in which acute mania or melancholia of a very violent type has resulted from cataclysmic emotions-if I may be permitted the term-such as the transport of accession to unanticipated fortune, the terror of being shut up in a house on fire, the agony of an accidental bereavement, or from a hurriedly heaped up intellectual load, such as the rubbish gathered together in a spurt at cramming, or the weighty masses of unaccustomed responsibility. To-day, however, I shall call your attention to some other cases in which protracted emotional tension, due to a succession of deluding joys, or sobering sorrows, or sustained intellectual strain, springing out of growing business engagements and calculations, or other arduous pursuits, have brought on fatuity, premature decrepitude and brain-wasting, and degeneration.

Unfortunately such cases are always abundant in this asylum, which derives its population from a busy district, one of the chief centres of high pressure both for boilers and brains, so that I shall have no difficulty in presenting you with illustrations of the condition which we are to consider. A very apt example exists in No. 2 Ward, in the person of W. W., whose case I would request you to note. This man, who is 45 years of age, was, until eighteen months ago, an energetic and prosperous accountant in a neighbouring large town, and occupied himself in public affairs, as well as in his private business. $\mathrm{He}$ worked late and early, lived in a vortex of rivalry and controversy, and greatly overtaxed his strength. At the time mentioned, he began to reap the fruits of his rashness; he felt ill ; he broke down in a speech which he was making, and he experienced a partial loss of power in his left arm and leg. He struggled on, however, as he could not afford even to pause in his career, and as he did so, his infirmities gained upon him. All mental processes became laborious, and many of them ended in confusion. His friends remarked that he was no longer the keen vigorous man that he had been, but dull and stupid, and at times depressed; that his voice had become shrill and tremulous, and his movements jerky and uncertain. Six months after the first indications of indisposition, his speech was almost lost, his left side was exceedingly weak, and his mind was reduced to a state of imbecility. In six months more, he was worse and pauperised, so that he had to be sent to this asylum, to which he was admitted on April 5th, 1870. Up to the present date, no improvement has taken place in his mental or bodily state ; indeed, he has declined steadily, in spite of treatment, into almost the last stage of brain-wasting, in which you now see him. You observe that he is a man with a large head, who has been much stouter than he now is, and whose general appearance is that of utter helplessness and second childishness. He cannot walk without assistance ; he shuffles his feet along the ground, and droops to the left side. His face is expressionless; his complexion exceedingly pallid. His tongue points to the left when protruded, and the pupil of his left eye is much larger than that of the right. His hands shake so, that when he attempts to feed himself he scatters his food about; they are also very feeble, especially the left, with which he cannot grasp anything. His command over language is very limited. He can say "book" and "pencil" when these articles are shown to him, but cannot form a sentence or give expression to his ideas. When he wishes to say something, his face brightens for an instant, he moves his hand impatiently before him, and is obviously groping for appropriate words ; but his efforts are vain, for he can only stutter out "fine day," or some mean. ingless phrase. When spoken to slowly and distinctly, he understands what is said to him, and will put out his tongue, take off his cap, or raise his hand, in accordance with the directions given. His emotions are also to some extent active, as he weeps when I speak to him of his family, and ask him if he desires to return home. Now, this man is, as I have said, almost in the last stage of brain-wasting, and has but a short time to live. After years of sustained pressure, intellectual and emotional, his brain has become deadened and degenerated. An insidious weakness has invaded all his powers. Without any apoplectiform seizure, he has become paralysed; without any paroxysm of excitement, he has grown fatuous. And when we come to examine his brain, we shall find that, without any traces of an inflammatory process, there is a distinct atrophy of that organ.

In order to exhibit to you the entire progress and results of brainwasting, I shall refer to the case of S. T., female, aged 54, who died in this asylum on January $25^{\text {th }}$ of the present year. She was brought hither from Selby on November I6th, I868, and was stated to have been a domestic servant, a hard-working woman, who had suffered many misfortunes, but who had always been of temperate and steady habits. The mind had given way some months before her reception here, its failure being evidenced by forgetfulness, and a constant fear that the police were about to take her into custody for some imaginary crime. At the time of her admission, she is reported as a tall woman, much emaciated, with a pale, deeply furrowed countenance, and in a dull lethargic mood, out of which she could scarcely be roused. She gazed vacantly around her, paused a long time before answering a question, and gave inconsequent and sometimes unintelligible replies. No clear account could be elicited from her of her past history, except as to some incidents of her girlhood, which she kept repeating. There was a systolic bruit at the base of her heart, and a thick white fur on her tongue, which corresponded to capriciousness of appetite and constipation of the bowels. A fortnight after her admission, she was in a drowsy semi-comatose state, out of which she emerged with thickness of articulation, inequality of the pupils-the left being contracted and the right dilated, general impairment of sensibility and muscular power, the failure of the latter being most marked on the right side. From that period her mental capacity became gradually more and more restricted. In the spring of 1869 she used to talk incoherently, or to spend days without moving or speaking ; sometimes requiring to be fed with the stomachpump, as she was too stupid to partake voluntarily of food. In the autumn of the same year, she was, if anything, less fatuous, and could answer "Yes" or "No" to simple questions ; but in the beginning of I 870 she sank into a stupor deeper than ever. She manifested no comprehension of what was said to her, and could only articulate a few monosyllables in a spluttering fashion. Her right hand was completely paralysed, and she could not totter along without being supported on both sides. Throughout the year she remained in the condition described, the prolongation of her life being solely attributable to the skilful nursing of which she had the benefit, and which actually carried her safely through a succession of carbuncles. In December I870, she was in the habit of uttering low monotonous automatic cries. In January 187 I, she was confined to bed altogether powerless, and demented. On the 25 th of that month, she died after a few hours of coma. At the post mortem examination, which took place sixty hours after death, the skull was found generally thickened and eroded by deer, rough channels for the meningeal vessels. It was unsymmetrical, bulging posteriorly to the left, and presented a bluish tinge in its inner table. The brain weighed forty ounces, and five ounces of clear serous fluid escaped during its removal. The arachnoid was thickened, and had a milky aspect over the frontal and parietal lobes. The pia mater was normal, and stripped freely from the convolutions, which were greatly attenuated, especially in the frontal and parietal lobes. The sulci were unusually large, and filled with fluid. The grey matter was pale and of faded appearance, and the white of a dusky colour, with numerous puncta vasculosa. The minute vessels seemed stronger and tougher than they ought to be. The ventricles were of immense size, and full of clear fluid. The fornix 
was softened, and the optic thalami were flattened and wasted. The pons Varolii, medulla oblongata, and cerebellum weighed five ounces. The thoracic and abdominal viscera were all more or less atrophied, but free from visible disease, except the liver, which was in a state of fatty degeneration.

In this description of the morbid appearances found in the body of $\mathrm{S}$. T., you have a vindication of the designation which we have applied to the malady under which she perished. Brain-wasting was certainly the essential pathological change discovered, and the only explanation of the symptoms displayed during life. The same description is applicable, almost word for word, to many other brains which you have had opportunities of seeing in our post mortem room here, and which all belonged to two classes of patients : first, those whose history and derangement were analogous to those of S. T.; and second, those who died of senile decay, or of other bodily diseases at a very advanced age. The brains of the old are undoubtedly wasted, and those others who have wasted brains are prematurely old. The excessive emotional or intellectual pressure to which we have adverted as the great cause of brain-wasting, really dissipates the energies of life, and induces a precocious dotage. The riotous living of the mind squanders that portion of strength bestowed upon it, and there is no fatted calf in this case to which the spendthrift may return. Decrepitude is the inevitable consequence. The prodigal is old before his time, and hurries through the ages of the worldplay into that mere oblivion which precedes the final exit. Hence the phenomena of his decline and fall are similar to those of old age, and the state of his brain after death is like that of the brain of an aged and infirm person. The brain of a man who has died in middle life from brain-wasting is not distinguishable from that of another man who has died of senile decay after a period of dotage. Both of them conform closely to the description given you of the brain of S. T. : diminished weight and bulk, general shrivelling, loss of the plumpness and roundness of the convolutions, expansion of the interspaces, and 'water, water everywhere' being the most important external characteristics. Having examined a large number of wasted brains, I am able to tell you that the wasting is never general and uniform throughout the brain, but seems to follow a definite course in all cases. It begins and is invariably most advanced in the marginal, the ascending frontal, and the ascending parietal gyri, from which it spreads to the superior frontal gyrus, and the postero-parietal and supramarginal lobules. After these it involves the middle or inferior frontal and the angular gyri. In severe and protracted cases, the gyri of the orbital lobule and of the tempero-sphenoidal lobe participate in the wasting, but those of the occipital lobe rarely, if ever, do so. You will frequently see the atrophy of the convolutions terminate abruptly at the external parieto-occipital fissure, the occipital lobe remaining plump, while the frontal and parietal are greatly attenuated. I cannot offer you any explanation of this partial distribution of the wasting, nor connect it in any way with the symptoms observed during life. I can only record its existence, as to which, indeed, you have frequent opportunities of satisfying yourselves. Along with the shrinking of the convolutions there is also wasting of the corpora striata, optic thalami, and corpora quadrigemina, which are flattened and altered in outline, the ventricles being unusually capacious. The wasting originates in the cortical substance of the hemispheres, but ultimately extends to the great ganglia at the base.

A state of brain-wasting very analogous to that which we are considering has been described by some as one result of alcoholismus chronicus. I shall hereafter point out to you that the atrophy of chronic intemperance has some peculiarities which separate it from simple brainwasting, both in the symptoms by which it is betrayed during life, and the appearances which it presents after death.

Having endeavoured to familiarise you with the essential nature and morbid anatomy of brain. wasting, I shall next direct your attention more particularly to its origin and development and symptoms, mental and bodily. As might have been expected, its presence is first announced by certain changes in mental processes. The cineritious substance is the first part of the cerebrum to undergo wasting, and suffers more seriously from atrophic changes than the encephalic ganglia. And hence mental precede motor symptoms. The intellect and emotions and appetites, which are dependent upon that cineritious substance for their manifestations, suffer decay earlier than the motor functions, which are dependent upon the encephalic ganglia. This fact, which I regard as certain, may not seem to you to be always borne out by the statements of the patients whom we examine, or of their relatives and friends. We are frequently told that the feeblenass of the arm, the drawing of the mouth, or the thickness of speech, was the first sign of illness noticed, and that until the appearance of the paralytic phenomena no mental failure or perversion had existed. Well, statements of that kind are never reliable ; and for this reason, that a man's mind may be very considerably weakened without his being at all alive to the fact, or without its being discovered by those who are living with him in familiar intercourse. He performs his ordinary everyday duties with his usual punctuality and precision, and it is not until attention is specially directed to him, or until some extraordinary exertion is required of him, that his deterioration becomes apparent. It is astonishing how little real thinking will suffice to carry a well trained-man through an average day or month of an average life. All sorts of subterfuges have been adopted to dispense with the trouble of original thinking. Counterfeits for thought have the freest circulation. Stock notions, habitual phrases, and second-hand maxims go a long way in place of thought, and entail no great exertion, as they depend upon familiar and almost automatic operations of the nervous centres. Even a damaged brain is equal to their evolution, and does not display its disability as long as it is called upon for no higher effort. The moment, however, that a greater or unaccustomed exercise is demanded, its prostration is lendered obvious. He who is labouring under a wasting bodily disease is seldom aware of his own degeneracy, until he endeavours to put forth his strength in some more than common effort; and so he who is labouring under brain-wasting may not detect the impairment of his mental powers, until he essays to employ his faculties in something beyond their routine occupation. Where we suspect brain-wasting, therefore, we must not be content when our patient assures us that his mind is sound, and his head as clear as ever. This may merely mean that he can eat his dinner with decency, remember the multiplication table, and wind up his watch. We must gauge his capacity in some less familiar field, put him through some mental gymnastics and exercises, and then determine, upon a consideration of his age, temperament, education, and position, whether his performance is as good as it ought to be. You must recollect the case of E. W. in which we had his own testimony and that of his relations at the time of his admission, that his intellect had retained its integrity for some months after muscular tremor had set in, and respecting whom we learnt from his employers afterwards that, for nearly two years prior to those tremors, he had been falling off from his usefulness as a clerk, and that, for three months before their occurrence, he had been committing preposterous blunders in his accounts.

As to the period of the recognition of those mental symptoms which mark the earliest stage of brain-wasting, a good deal depends upon the position of the sufferer. If that is such as to call for a display of mental power, then they will be early detected; if not, then they will not improbably be overlooked until paralytic symptoms supervene. In $M$. G. aged 38, a Jewish rabbi, who died here from brain-wasting, brought on by anxiety and over-work extending over many years spent in Austria and in this country, mental failure was revealed in his repeating himself in his sermons, and in errors and omissions in the services, fully four months before a convulsive fit ushered in the paralytic symptoms. But in G. W., aged 46, a labourer, broken down by domestic miseries, who also died here from brain-wasting, last year, no mental curtailment was noticed until paralysis affected his right side. In the upper ranks of society the mental symptoms will, as a rule, be more promptly appreciated both by the sufferer himself and by those around him, than amongst the lower classes. In the latter the tendency of life is to induce bluntness and insensibility, to limit the range of the senses and emotions, to place them beyond the reach of any but powerful stimulants, to shut out petty pains and annoyances, and at the same time small pleasures and beatitudes. The working man must not notice the cut finger, the broken nail, the pinching shoe, the drain-smell, the noise of adjoining machinery, the unmerited reproof; and, consequently, he is inaccessible to delicate sensations of bodily well-being or derangement, and to the finer indications of mental decay. He relishes no flavour milder than onions, and acknowledges no mental disorders short of complete anarchy. In the upper ranks, however, the tendency is to open the senses and mind to the most airy and evanescent impressions, to make them responsive to the slightest touch. Sheltered from rough usage or discordant accompaniments, and solicited by bland and delighful environments, the tenderly bred lady becomes exquisitely sensitive, and is quick to remark any deviation from health in her own mind or that of any one in whom she is interested. The brain-wasting of my lord, therefore, is recognised in its incipient mental manifestations, while that of Hodge has advanced far into paralysis before its presence is suspected. [To be continued.]

OWens College Extension.-We (Manchester Guardian) understand that Miss Brackenbury has signified her intention to give the magnificent sum of $£ 10,000$, for the establishment of a medical school in connection with the College, being $€ 5,000$ for the erection of suitable buildings, and $£ 5,000$ by way of endowment for the support of the department. We believe that the father of Miss Brackenbury was in the medical profession, and it would be a graceful recognition of the fact for the governors to endow a Brackenbury professor. 